\section{THE ETHICS CRUNCH: CAN MEDICAL SCIENCE ADVANCE WITHOUT THE USE OF ANIMALS?}

\author{
Reverend Gary Kowalski \\ Burlington, Vermont
}

\section{Presented at a public forum sponsored by The Center for Ethics and Public Policy Seattle, Washington March 5, 1989}

The great scientist Charles Darwin wrote, "Everyone has heard of the dog suffering under vivisection, who licked the hand of the operator; this man, unless the operation was fully justified by an increase of our knowledge, or unless he had a heart of stone, must have felt remorse to the last hour of his life."

"You ask my opinion on vivisection. I quite agree that it is justifiable for real investigations on physiology; but not for mere damnable and detestable curiosity. It is a subject which makes me sick with horror, so I will not say another word about it, else I shall not sleep tonight."

The conflict Darwin experienced in regard to vivisection is one many thinking people share. When Darwin lived, over a century ago, the campaign against it had just begun. At that time, several hundred animals died each year under the operator's knife. Today, between 20 and 70 million perish annually in laboratories in the United States alone. They are crushed in impact studies, blinded with chemical irritants, poisoned in toxicology research, and infected with painful and deadly diseases. It is not un-scientific or sentimental to ask if all these deaths are really necessary. Could human health be maintained with less agony among our neighbors in the natural world? Answering that question involves technical arguments over the extent to which animal experimentation can be replaced by research techniques employing tissue cultures,

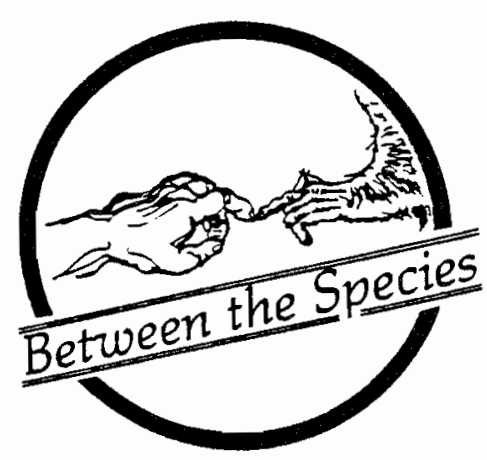

computer modeling, clinical and epidemiological studies, and the use of non-sentient organisms. There are scientific arguments on both sides.

But this is not simply a scientific issue. It is also an ethical and religious issue. For the current debate about the use of animals in research centers around a moral question: whether nonhuman species have a value intrinsic to themselves, or whether their worth is purely instrumental, dependent upon their usefulness to human beings. The religious heritage stemming from the Bible taught that man is to have dominion over the beasts, and ethical theorists from Aquinas to Kant have echoed the lesson that animals are beyond the scope of our moral concern. The dominant view of Western culture has been that animals have only extrinsic worth. A rabbit, for instance, has no importance in itself. It's life is significant only because it provides a source of food and fur, and because it can serve as a research tool. For those who believe animals exist to be exploited, vivisection presents no moral problem. We are justified in using animals in any manner that might conceivably result in human advantage.

It was no accident that Charles Darwin had qualms about vivisection, for he was one of those who helped overturn the anthropocentric world view of the Bible, and made us understand that homo sapiens is only one species in a great continuum of life. Today, in our ecologically

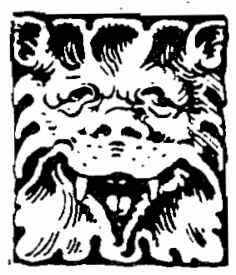

COMMENT 
conscious society, more and more people have come to believe that animals are not only our biological kin. They are also related to us morally and spiritually. Like human beings, animals possess an inherent worth. They have a value quite apart from their potential to be used in testing new drugs or cosmetics. And this insight is at the heart of the movement for "animal rights."

In thinking about this issue, it might be helpful to ask what we mean by a "right." The word is often used in two slightly different senses. First of all, there are legal rights. To have a "right" in this sense implies that one receives certain judicial guarantees of protection from outside control or exploitation. Legal rights, as we understand them, developed out of Common Law. In the beginning, English barons asserted their rights against the king. Later, important rights were extended to other male property-holders. In comparatively recent times, women and children were also granted rights so they could no longer be beaten or abused by their 'masters' without legal consequences. To say that animals should have rights is simply to suggest that certain procedural safeguards should govern our treatment of animals, with legal penalties to follow when those safeguards are sidestepped or violated.

But do animals deserve such safeguards? This raises the question of "rights" in its broader moral and philosophical sense, for legal rights are generally presumed to rest on underlying "natural rights." It is stated in our Declaration of Independence, for example, that "all men (sic) are created equal and endowed by their Creator with certain inalienable rights." Now in what way are people equal to one another? Certainly not in brain power. Not in verbal ability, nor in the ability to solve problems. They are equal only in this respect: that the life of the very humblest individual is as dear to him as the life of the greatest and most gifted is to him. What gives us rights as human beings, therefore, is not how well we speak or reason. Rather it is the fact that we have "interests." We are ends as well as means. We have an existence that is "for ourselves" and not simply for the benefit of others. No matter how modest our intellectual attainments, we are more than property and more than things or objects.

Animal rights, advocates believe that apes, mice, pigeons and dogs are also more than things or objects. True, most animals lack a genuine language. Their intelligence is of a different order than our own. Still, animals are more than personal property or natural resources. They are independent beings with needs and interests of their own, and like human beings they suffer physically and mentally when those needs are not respected. This suffering deserves to be taken into account and weighed in the ethical balance whenever the interests of humans and non-humans are in conflict.

Too often research on animals involves gratuitous suffering. The LD-50 test, which attempts to establish the lethal dose of a test substance by force feeding it to an experimental group of animals until half die; is not required by any federal safety standards, is virtually meaningless from a medical standpoint, and yet continues to result in the death of four to five million rodents, dogs, and primates every year. Each year, another five or six million animals die needlessly for purposes of education, as in high school dissections where a teacher's demonstration or a film could easily be substituted to teach anatomy. Instances of deliberate cruelty also exist, like the head injury studies at the University of Pennsylvania which finally shocked Congress into amending the Animal Welfare Act. Such abuses are exposed and ended, not because of any selfpolicing or tender-heartedness on the part of the research establishment, but only because of the vigilant work of animal activists.

Are experiments with animals ever justified? Perhaps. If sacrificing the life of a hamster or guinea pig meant saving the life of a child, the decision would be easy. But the choices in real life are seldom so clearcut. The best advice may have come from Albert Schweitzer, who wrote:

Those who carry out scientific experiments with animals, in order to apply the knowledge gained to the alleviation of human ills, should never reassure themselves with the generality that their cruel acts serve a useful purpose. In each individual case they must ask themselves whether there is a real necessity for imposing such a sacrifice upon a living creature. They must try to reduce suffering insofar as they are able. 
Unfortunately, not every experimenter will follow Schweitzer's advice. So the answer is to open the labs to public inspection. Create ethical review committees that represent a true crosssection of the community, and that are not merely hand-picked rubberstamps for the vivisectionist lobby. If animal research actually benefits the public, surely it has nothing to fear from public scrutiny. What the animal activists are demanding is neither wild-eyed nor radical: Take the "no admittance" signs off the laboratories. Take the locks off the doors.

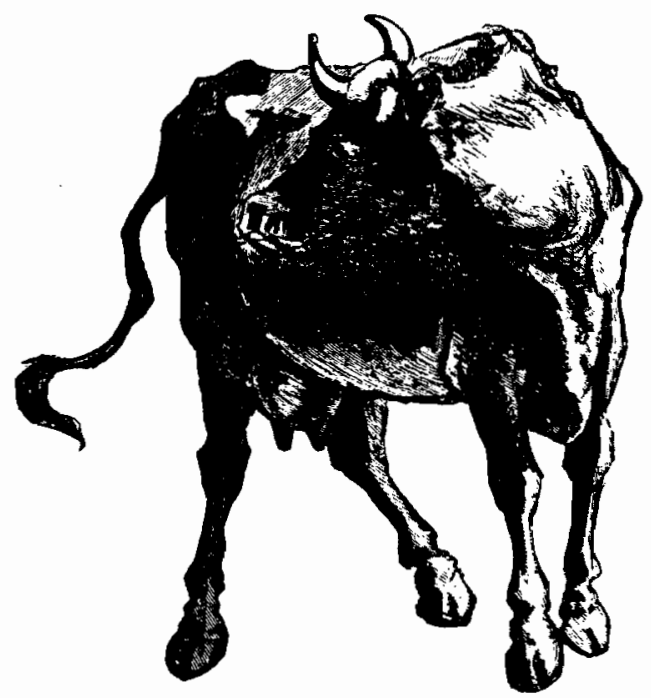

If You Really Care About Animals, You Need to Read The ANIMALS' AGENDA

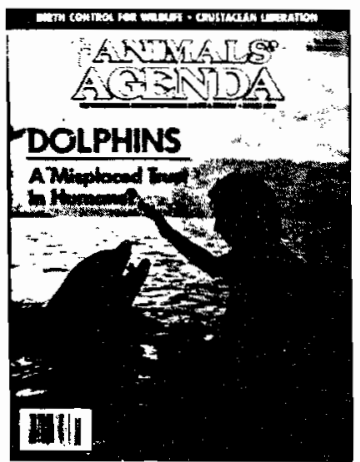

To say you love animals is one thing. but it's important to know what you're talking about if you're really going to do something to help them.

Covering a range of issues from factory farming to Native trapping. from endangered species to companion animals, we have been a valuable resource for nine years. We are your best connection with the people and events that are making animal rights one of the major movements of the twentieth century. ENTERANS A(G) $\cong \sqrt{0 / A}$

The International Magazine of Animal Rights \& Ecology

YESI I want to subscribe to YES! The ANIMALS' AGENDA.

$$
\begin{aligned}
& =1 \text { yr. } \$ 22 \square 2 \text { yrs. }-\$ 39 \square 3 \text { yrs.-\$55 } \\
& \text { (Ten issues) } \\
& \text { Name } \\
& \text { Adcress__tate_zip _ } \\
& \text { City_ The ANIMALS' AGENDA } \\
& \text { Subscription Dept. } \\
& \text { P.O. Box } 6809 \bullet \text { Syracuse, NY } 13217
\end{aligned}
$$

